\title{
Clinical outcomes of over-the-scope-clip system for the treatment of acute upper non-variceal gastrointestinal bleeding: a systematic review and meta-analysis
}

\author{
Chunyu Zhong ${ }^{1 \dagger}$, Shali Tan ${ }^{1 \dagger}$, Yutang Ren ${ }^{2+}$, Muhan Lü ${ }^{1}$, Yan Peng ${ }^{1}$, Xiangsheng Fu ${ }^{3^{*}}$ and Xiaowei Tang ${ }^{{ }^{*}}$
}

\begin{abstract}
Background: Conventional endoscopic treatments can't control bleeding in as many as $20 \%$ of patients with nonvariceal gastrointestinal (GI) bleeding. Recent studies have shown that over-the-scope-clip (OTSC) system allowed for effective hemostasis for refractory GI bleeding lesions. So we aimed to conduct a systematic review to evaluate the effectiveness and safety of the OTSC system for management of acute non-variceal upper Gl bleeding.

Method: A comprehensive literature search was conducted on PubMed, EMBASE, and Cochrane Library covering the period from January 2007 to May 2019. The literature was selected independently by two reviewers according to the inclusion and exclusion criteria. The statistical analysis was carried out using Comprehensive Meta-Analysis software version 3.0.

Results: A total of 16 studies including 769 patients with $778 \mathrm{Gl}$ bleeding lesions were identified. Pooled technical success was achieved in 761 lesions [95.7\%; 95\% confidence interval (CI), 93.5-97.2\%], and the pooled clinical success was achieved in 666 lesions $(84.2,95 \% \mathrm{Cl}, 77.4-89.2 \%)$. The incidence of re-bleeding was reported in 81 patients and the post-procedure mortality was $10.9 \%(n=84)$. Only $2(0.3 \%)$ patients occurred complications after OTSC system procedure.
\end{abstract}

Conclusions: Our study demonstrated that the OTSC system was a technically feasible modality and highly efficacious in achieving hemostasis in acute non-variceal upper gastrointestinal bleeding.

Keywords: Endoscopic, Gastrointestinal bleeding, Over-the-scope clip, Systematic review, Meta-analysis

\section{Background}

Upper gastrointestinal bleeding is preponderantly nonvariceal in origin and remains one of the commonest challenges faced by endoscopists in daily clinical practice. It is estimated that the incidence of annual acute upper non-variceal gastrointestinal bleeding (UNVGIB) ranges between 50 and 160 cases per 100,000 and

\footnotetext{
* Correspondence: drfuxs@gmail.com; solitude5834@hotmail.com ${ }^{\dagger}$ Chunyu Zhong, Shali Tan and Yutang Ren contributed equally to this work. ${ }^{3}$ Department of Gastroenterology, Affiliated Hospital of North Sichuan Medical College, Road Wenhua 63\#, Region Shunqing, Nanchong 637000, Sichuan, China

${ }^{1}$ Department of Gastroenterology, Affiliated Hospital of Southwest Medical University, Street Taiping No.25, Region Jiangyang, Luzhou 646099, Sichuan Province, China

Full list of author information is available at the end of the article
}

commonly requires hospitalization [1]. Despite crucial advances in the treatment of UNVGIB over the past decade, including optimal use of endoscopic therapy and high-dose proton pump inhibition, UNVGIB still carried considerable morbidity, mortality and health economic burden [2]. The majority of UNVGIB could be managed by conventional endoscopic interventions. However, some studies have shown that conventional therapies such as epinephrine injections and hemoclips or coagulation could not achieve successful hemostasis in 4 to $20 \%$ of UNVGIB cases, and even caused severe complications [3-8].

Hence, there was an urgent need for a safe and more effective endoscopic treatment modality for UNVGIB cases. Recently, a novel endoscopic device, called Over- 
the-scope clip (OTSC) system has been developed. The OTSC system is a clipping device made of nitinol, and easily attached to the tip of the scope. By a procedure similar to ligation of esophageal varices, it can be readily released at the site of the bleeding site. Since the first report of the successful application of OTSC in GI bleeding by Kirschniak et al. in 2007 [9], there have been many prospective or retrospective studies reported OTSC system to manage the UNVGIB. Thus, we aimed to perform a systematic review and structured metaanalysis of all eligible studies to evaluate the effectiveness and safety of OTSC system in patients with UNVGIB.

\section{Methods}

\section{Search strategy}

This meta-analysis was conducted in accordance with Preferred Reporting Items for Systematic Reviews and Meta-Analyses (PRISMA) guidelines [10]. For this topic, the participants were the patients with acute upper nonvariceal gastrointestinal bleeding, the intervention was a treatment method of OTSC, and the outcome was the success rate.

Studies published in PubMed, Embase and Cochrane library from January 2007 to May 2019 was searched systematically using the following search terms, "OTSC system", "over the scope clip", "OVESCO", "gastrointestinal bleeding", "ulcer bleeding", "melena", "hemorrhage", "hemostasis" and others. The terms were used in all possible combinations to obtain the maximal number of articles. Additional file 1: Table S1 showed the search strategy of each of search engines. The identified studies were subsequently screened for duplicates and relevance on the subject by their abstracts. Two reviewers independently searched literature and reviewed of the identified studies for eligibility. If there was any disagreement, it could be resolved through discussion between the two reviewers or judged with the assistance of a third party.

\section{Criteria for inclusion and exclusion}

Studies reporting primary data in which UNVGIB was managed with OTSC system were included. Essential results were defined as following: primary hemostasis defined as no re-bleeding immediately after OTSC placement. Primary failure defined as continuous bleeding after OTSC placement. Re-bleeding was defined as development of fresh hematemesis, melena, hematochezia, shock, or a drop in hemoglobin of more than $2 \mathrm{~g} / \mathrm{dL}$ within $24 \mathrm{~h}$, with need for repeat treatment [11-13]. Technical success defined as successful placement of the OTSC on the target lesion. Clinical success defined as having no primary failure and no re-bleeding during follow-up. The above results must be reported in included studies. Only studies in English were included. And series with more than 5 cases described were included. Vivo trials were excluded. Chronic bleeding was excluded as well.

\section{Data extraction}

The following data were extracted from each study: (a) study characteristics, including the author name, the publication country, publication year, type of study, sample size, age, gender, lengths of follow-up, and (b) clinical features of use OTSC system managing bleeding lesion, including indication, bleeding classification, number of patients receiving an antithrombotic, technical success, clinical success, re-bleeding, number of OTSC system deployments, number of blood units transfusion, number of patients requiring additional surgical procedures, complications and mortality.

\section{Study quality}

Downs and Black checklist were used to evaluate the quality of the included studies [14]. We scored each study in accordance with the evaluation scale, high methodological quality articles were defined as scoring higher than 19, moderate quality articles as scoring 15 to 19 , moderate to low-quality articles as scoring 10 to 14 , and low quality articles as scoring lower than 10.

\section{Statistical analysis}

Continuous data are presented as the mean \pm standard deviation (SD) or variation range. The statistical analysis was carried out using Comprehensive Meta-Analysis software version 3.0. The overall success rate of clinical trials was expressed by the pooled proportion with 95\% confidence intervals $(\mathrm{CI})$, which was presented as forest plots. Statistical heterogeneity of included studies was evaluated using Cochran Q test and $I^{2}$ statistic, $I^{2}$ value of greater than $50 \%$ or a $P$ value of less than 0.05 for the $Q$ statistic was considered to indicating significant heterogeneity. Then, the pooled proportion used a randomeffects model or fixed-effects model. Publication bias was assessed via visual inspection of the funnel plot and Egger's test, the $P$ value of greater than 0.05 was considered to no publication bias [15].

\section{Results}

\section{Included studies}

The initial search terms identified 1032 studies after duplicates removed. Of these, 983 studies were excluded according to the predefined criteria and 49 studies were reviewed the full-text. Final literature search and selection according to the inclusion and exclusion criteria yielded 16 studies about OTSC system treatment for UNVGIB [11-13, 16-28]. Figure 1 showed the search and selection process. 


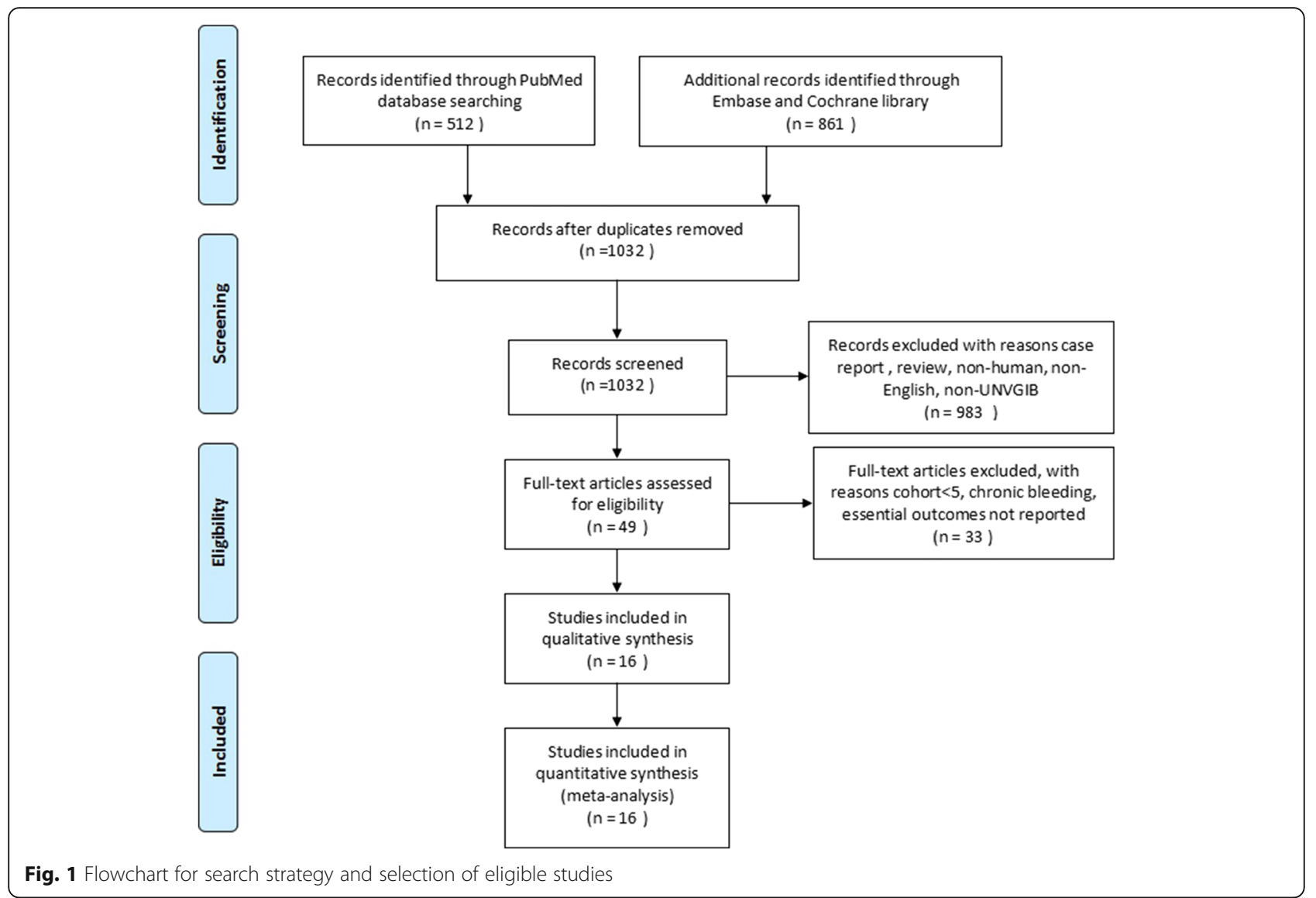

\section{Studies characteristics}

Studies characteristics are summarized in Table 1. All the studies were published between 2011 and 2019, and most studies published in Germany $(n=7)$. Only one prospective randomized trial was included [26], and the remaining studies were retrospective studies $(n=13)$ or prospective studies $(n=2)$.

A total of 769 patients with 778 GI bleeding lesions was managed by OTSC system. Among them, OTSC system was used as the primary treatment modality in 507 lesions, while 190 lesions as rescue treatment modality after previous endoscopic treatment failure. Only 10 studies included 501 patients reported the patients' gender and age. Of them, 303 (60.5\%) patients were male, and the mean age ranged from 59 to 77 years. Follow-up time was reported in 8 studies, with at least 1 month.

\section{Clinical outcomes}

The etiology of acute upper non-variceal gastrointestinal bleeding was available in 14 studies. As shown in Fig. 2, the major cause was peptic ulcer $(n=446,75.59 \%)$, the remain causes were Mallory-Weiss lesion $(n=38$, $6.44 \%)$, post-endoscopic procedures $(n=33,5.59 \%)$, anastomosis $(n=29,4.92 \%)$, dieulafoy lesion $(n=31$,
$5.25 \%)$, tumor $(n=11,1.86 \%)$ and others $(n=2,0.34 \%)$. There were 7 studies reporting patients who were under the antithrombotic therapy, the proportion of which rang from 16.7 to $75.6 \%$. The average length of hospital stays reported in 4 studies, which range from 4 to 19.8 days. Additionally, 13 studies reported 81 patients occurred re-bleeding, and the rate varied from 0 to $35.3 \%$. The number of OTSC system deployment per lesion was reported in 8 studies, varying from 1 to 2 . Six studies reported the patients received transfusion red blood cells, the mean number of blood units transfused ranged from 0 to 5.1 units (Table 2).

Figure 3 showed the pooled technical success of OTSC system which was achieved in 761 lesions (95.7\%; 95\%CI, 93.5-97.2\%). Heterogeneity was not significant among the studies $\left(I^{2}=24.5 \%, P=0.177\right)$. Figure 4 showed the pooled clinical success was achieved in 666 lesions (84.2\%; 95\% CI, 77.4-89.2\%). Heterogeneity was significant among the studies $\left(I^{2}=69.5 \%, P=0.000\right)$. However, a total of 63 patient required additional endoscopic therapy, surgery or vascular embolization. We also conducted subgroup analysis to identify the effect of study period and study sample size in the OTSC treatment in UNVGIB. Nine studies $(n=218)$ were published 
Table 1 Characteristics of included studies

\begin{tabular}{|c|c|c|c|c|c|c|c|c|}
\hline Study & $\begin{array}{l}\text { Country of } \\
\text { publication }\end{array}$ & $\begin{array}{l}\text { Year of } \\
\text { publication }\end{array}$ & Study design & Patient, $\mathrm{n}$ & $\begin{array}{l}\text { Lesion, } \mathrm{n} \\
\text { (P/R) }\end{array}$ & Age (years) & $\begin{array}{l}\text { Gender } \\
\text { (M:F) }\end{array}$ & $\begin{array}{l}\text { Mean follow-up time } \\
\text { (range) }\end{array}$ \\
\hline Kirschniak et al. [16] & Germany & 2011 & Retrospective & 12 & $12(-/-)$ & - & - & - \\
\hline Albert et al. [17] & Germany & 2011 & Retrospective & 6 & $6(2 / 4)$ & - & - & At least 1 month (-) \\
\hline Manta et al. [18] & Italy & 2013 & Retrospective & 23 & $23(0 / 23)$ & - & - & At least 1 month $(-)$ \\
\hline Mönkemüller et al. [19] & United States & 2014 & Retrospective & 6 & $6(0 / 6)$ & $72 \pm 14.5$ & $4: 2$ & - \\
\hline Chan et al. [11] & China & 2014 & Prospective & 9 & $9(3 / 6)$ & $72.5(39-89)$ & $4: 5$ & - \\
\hline Skinner et al. [12] & United States & 2014 & Retrospective & 12 & $12(0 / 12)$ & $59(29-86)$ & $8: 4$ & At least 1 month (-) \\
\hline Manno et al. [20] & Italy & 2016 & Retrospective & 40 & $40(40 / 0)$ & $69(25-94)$ & $33: 7$ & At least 1 month $(-)$ \\
\hline Wedi et al. [21] & France & 2016 & Retrospective & 41 & $41(13 / 28)$ & - & - & - \\
\hline Richter-Schrag et al. [22] & Germany & 2016 & Retrospective & 63 & $69(39 / 30)$ & $68(27-92)$ & $38: 25$ & - \\
\hline Lamberts et al. [23] & Germany & 2017 & Retrospective & 68 & $68(-/-)$ & - & - & - \\
\hline Goenka et al. [24] & India & 2017 & Prospective & 6 & $6(0 / 6)$ & $62 \pm 13.1$ & $5: 1$ & At least 1 month (1-1.4) \\
\hline Wedi et al. [25] & Germany & 2017 & Retrospective & 118 & $120(120 / 0)$ & $71 \pm 12.4$ & - & - \\
\hline Schmidt et al. [26] & Germany & 2018 & $\begin{array}{l}\text { Prospective } \\
\text { randomized trial }\end{array}$ & 33 & $33(0 / 33)$ & 77 (33-90) & 20:13 & At least 1 month $(-)$ \\
\hline Asokkumar et al. [27] & Singapore & 2018 & Retrospective & 18 & $19(10 / 9)$ & $68 \pm 15.9(22-91)$ & $12: 6$ & At least 1 month $(-)$ \\
\hline Manta et al. [13] & Italy & 2018 & Retrospective & 214 & $214(214 / 0)$ & $66 \pm 10.2$ & $115: 99$ & At least 1 month (-) \\
\hline Gölder et al. [28] & Germany & 2019 & Retrospective & 100 & $100(66 / 34)$ & 76 (20-98) & $64: 36$ & - \\
\hline
\end{tabular}

M:F male to female, $P$ primary treatment, $R$ rescue treatment

between 2011 and 2016, while 7 studies $(n=560)$ were publised between 2017 and 2019. Subgroup analysis showed the clinical success rate was 86.5\% (95\%CI, $80.7-90.7 \%)$ and $82.3 \%$ (95\% CI, 70.3-90.1\%), respectively (Fig. 5). The number of studies with less than 30 patients or these with greater than or equal to $30 \mathrm{pa}$ tients was same $(n=8)$. Subgroup analysis showed the clinical success rate was 79.9\% (95\% CI, 69.9-87.3\%) and 86.6\% (95\% CI, 76.6-91.6\%), respectively (Fig. 6).

\section{Adverse events}

Most of the involved studies reported no complication occurred related to OTSC system. Complications just occurred on $2(0.3 \%)$ patients after application OTSC system. One case occurred on a duodenal ulcer bleeding patient who experienced a tiny GI leak which was suspected to be caused by the clip. Another adverse event was lumen obstruction after a duodenal OTSC application. None of these studies reported severe and fatal

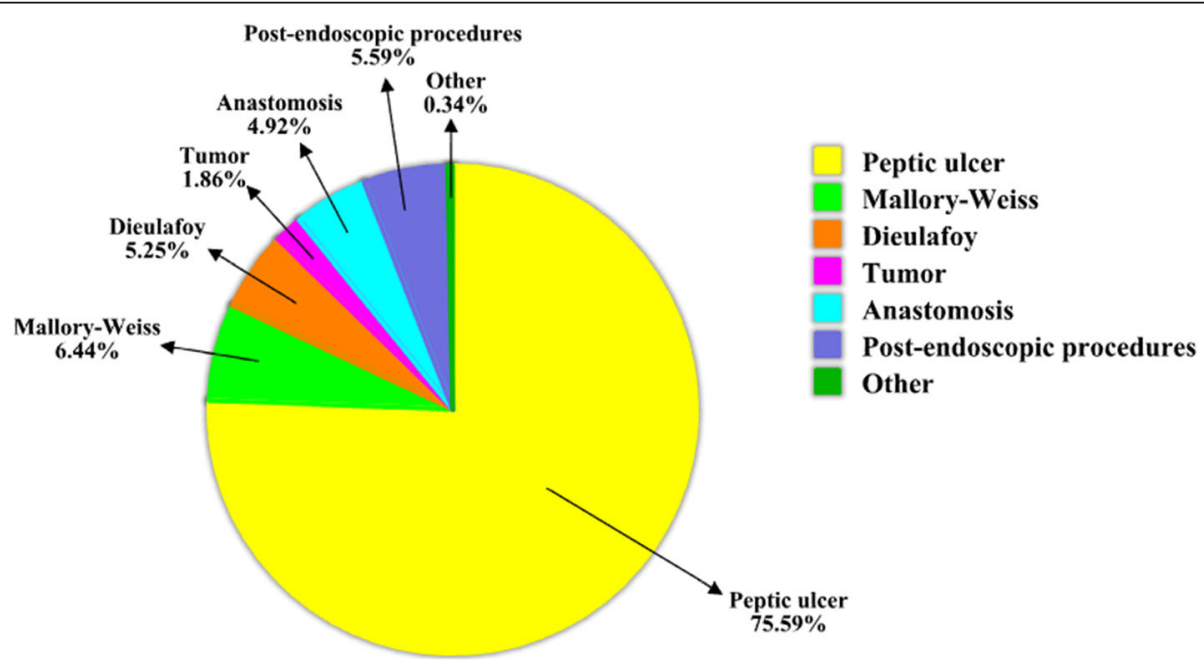

Fig. 2 Chart for the proportion of acute upper non-variceal gastrointestinal bleeding etiology (Post-endoscopic procedures: after gastric biopsy, gastric polypectomy, endoscopic ultrasonography guided fine needle aspiration of peri-gastricmass, endoscopic mucosal resection and endoscopic submucosal dissection; Others: balloon dilation for achalasia and vascular malformation) 


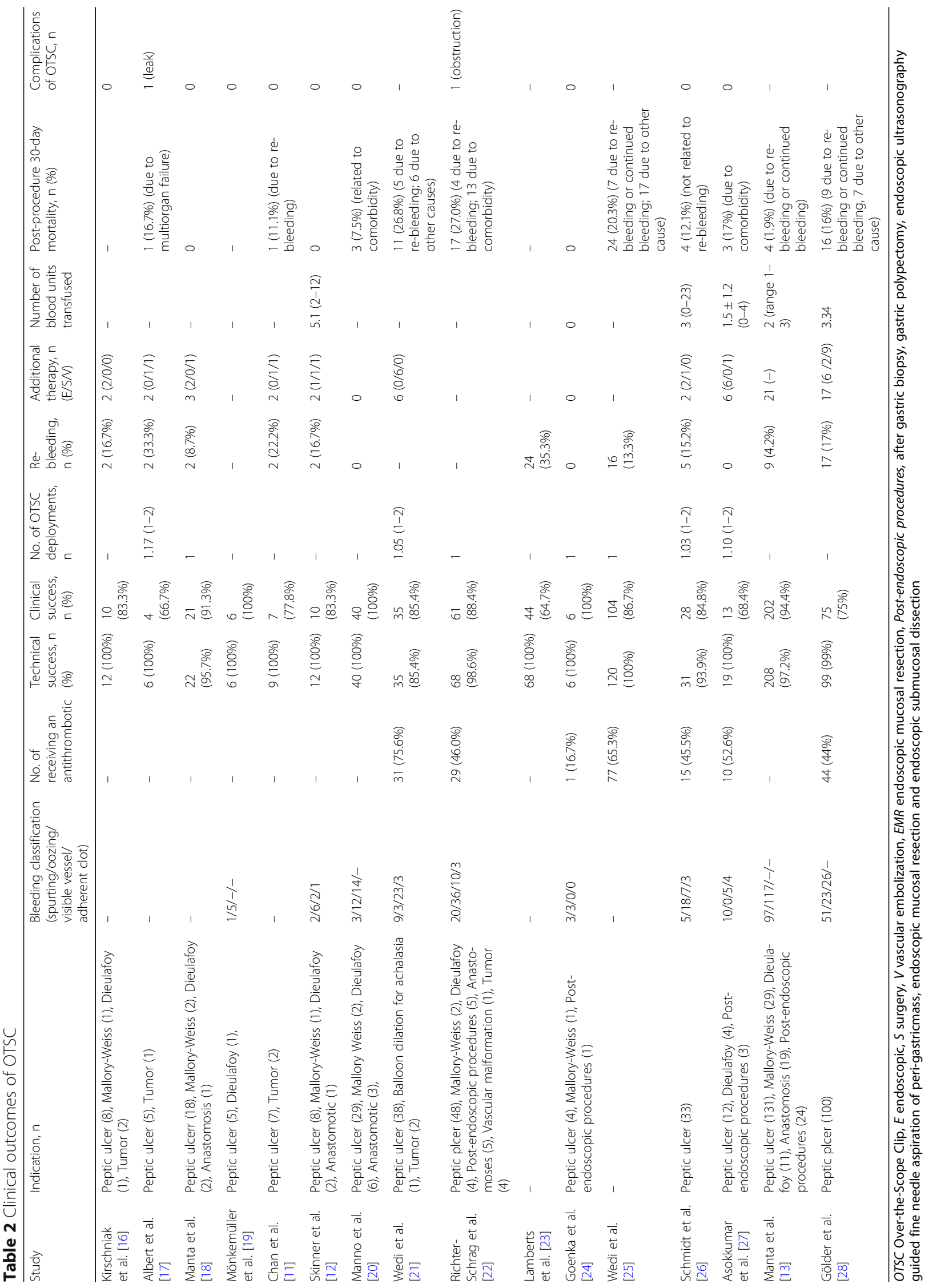




\begin{tabular}{lcccrrr}
\cline { 3 - 5 } Study name & \multicolumn{5}{c}{ Statistics for each study } \\
\cline { 3 - 6 } & $\begin{array}{c}\text { Event } \\
\text { rate }\end{array}$ & $\begin{array}{c}\text { Lower } \\
\text { limit }\end{array}$ & $\begin{array}{c}\text { Upper } \\
\text { limit }\end{array}$ & Z-Value & p-Value \\
Kirschniak et al. 2011 & 0.962 & 0.597 & 0.998 & 2.232 & 0.026 \\
Albert et al. 2011 & 0.929 & 0.423 & 0.996 & 1.748 & 0.081 \\
Manta et al. 2013 & 0.957 & 0.748 & 0.994 & 3.023 & 0.003 \\
Monkemüller et al. 2014 & 0.929 & 0.423 & 0.996 & 1.748 & 0.081 \\
Chan et al. 2014 & 0.950 & 0.525 & 0.997 & 2.029 & 0.042 \\
Skinner et al. 2014 & 0.962 & 0.597 & 0.998 & 2.232 & 0.026 \\
Manno et al. 2016 & 0.988 & 0.833 & 0.999 & 3.088 & 0.002 \\
Wedi et al. 2016 & 0.854 & 0.710 & 0.933 & 3.991 & 0.000 \\
Richter-Schrag et al. 2016 & 0.986 & 0.904 & 0.998 & 4.189 & 0.000 \\
Lamberts et al. 2017 & 0.993 & 0.895 & 1.000 & 3.466 & 0.001 \\
Goenka et al. 2017 & 0.929 & 0.423 & 0.996 & 1.748 & 0.081 \\
Wedi et al. 2017 & 0.996 & 0.937 & 1.000 & 3.870 & 0.000 \\
Schmidt et al. 2018 & 0.939 & 0.788 & 0.985 & 3.757 & 0.000 \\
Asokkumar et al. 2018 & 0.975 & 0.702 & 0.998 & 2.558 & 0.011 \\
Manta et al. 2018 & 0.972 & 0.939 & 0.987 & 8.563 & 0.000 \\
Golder et al. 2019 & 0.990 & 0.932 & 0.999 & 4.572 & 0.000 \\
& 0.957 & 0.935 & 0.972 & 14.050 & 0.000
\end{tabular}

\section{Event rate and $95 \% \mathrm{Cl}$}

026

0.081

0.042

0.026

0.000

0.000

0.001

0.081

0.000

0.000

0.000

.000

Fig. 3 Forest plot of technical success of over-the-scope clip for acute upper non-variceal gastrointestinal bleeding

complication. Twelve studies reported the mortality rate was $10.9 \%(n=84)$, which related to re-bleeding or continued bleeding was 3.9\% $(n=30)$ and due to other causes were $7.0 \%(n=54)$.

\section{Quality of included studies}

Table 3 showed the quality scores of each study according to the Downs and Black checklist. Five studies scored low methodological quality (score range 8 to 9 ), 8 studies scored low to moderate quality (score range 10 to 14), two study scored moderate-quality (score range 15 to 17), and one study which was randomized trial scored 20 considered as high-quality.

\section{Publication Bias}

Funnel plot of technical success and clinical success was demonstrated in Fig. 7 and Fig. 8. Through visual inspection of the funnel plot, no publication bias can be generally considered. By Egger's test, technical success rate $(P=0.123)$ and clinical success rate $(P=0.346)$ had no significant publication bias.

\section{Discussion}

UNVGIB is a common and potentially life-threatening emergency. Currently, endoscopic hemostatic treatment has been a gold standard therapy for UNVGIB, which included endoscopic hemoclips, thermal therapy and

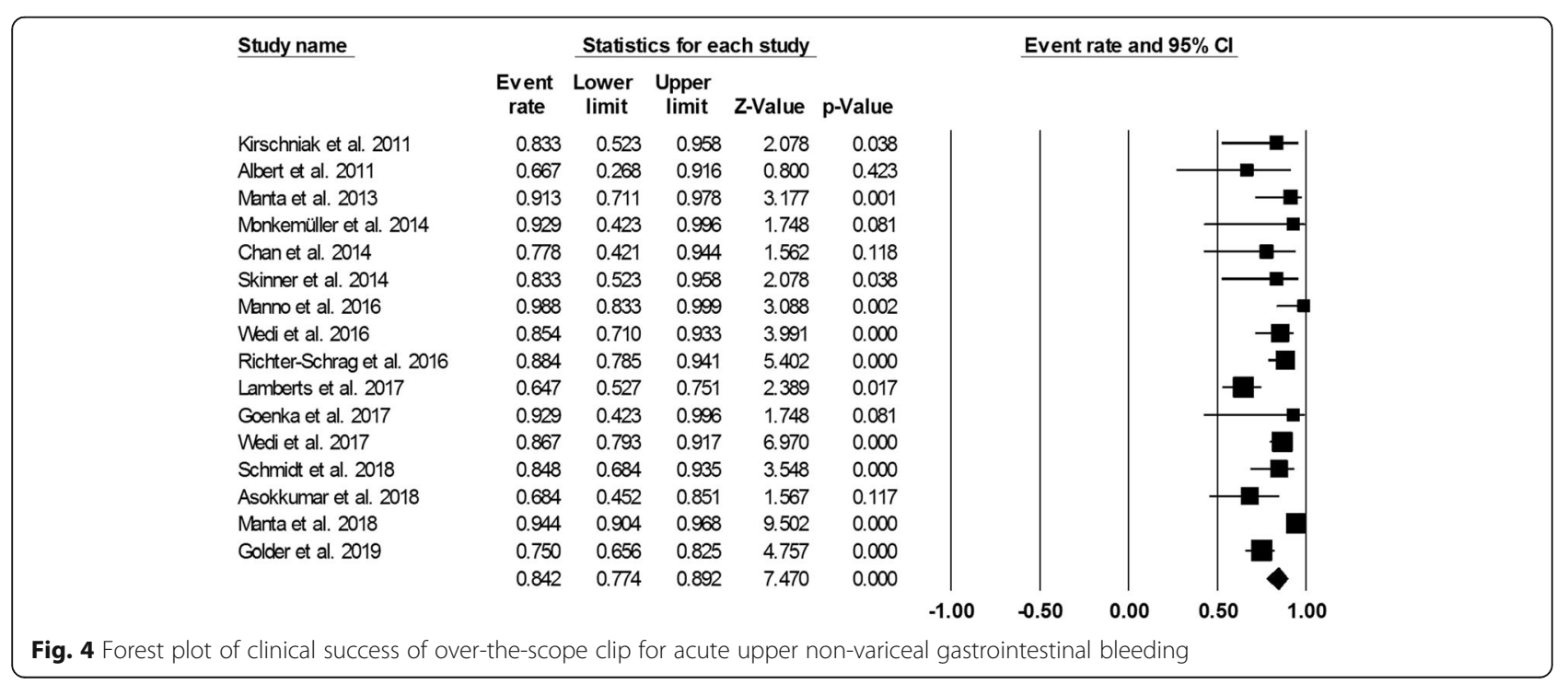




\begin{tabular}{|c|c|c|c|c|c|c|c|c|c|c|c|c|}
\hline \multirow[t]{13}{*}{ A } & Studyname & \multirow[t]{2}{*}{ Subgroup within study } & \multicolumn{5}{|c|}{ Statistics for each study } & \multicolumn{5}{|c|}{ Event rate and $95 \% \mathrm{Cl}$} \\
\hline & & & $\begin{array}{c}\text { Event } \\
\text { rate }\end{array}$ & $\begin{array}{l}\text { Lower } \\
\text { limit }\end{array}$ & $\begin{array}{l}\text { Upper } \\
\text { limit }\end{array}$ & z-Value & $\mathrm{p}$-Value & & & & & \\
\hline & Albert et al. 2011 & 2011-2016 & 0.667 & 0.268 & 0.916 & 0.800 & 0.423 & & & & & \\
\hline & Chan et al. 2014 & 2011-2016 & 0.778 & 0.421 & 0.944 & 1.562 & 0.118 & & & & & \\
\hline & Kirschniaket al. 2011 & $2011-2016$ & 0.833 & 0.523 & 0.958 & 2.078 & 0.038 & & & & & - \\
\hline & Manno et al. 2016 & $2011-2016$ & 0.988 & 0.833 & 0.999 & 3.088 & 0.002 & & & & & \\
\hline & Manta et al. 2013 & $2011-2016$ & 0.913 & 0.711 & 0.978 & 3.177 & 0.001 & & & & & \\
\hline & Monkemüler et al. 2014 & $2011-2016$ & 0.929 & 0.423 & 0.996 & 1.748 & 0.081 & & & & & \\
\hline & Richter-Schrag et al. 2016 & $6 \quad 2011-2016$ & 0.884 & 0.785 & 0.941 & 5.402 & 0.000 & & & & & \\
\hline & Skinner et al. 2014 & 2011-2016 & 0.833 & 0.523 & 0.958 & 2.078 & 0.038 & & & & & \\
\hline & Wedi et al. 2016 & $2011-2016$ & 0.854 & 0.710 & 0.933 & 3.991 & 0.000 & & & & & \\
\hline & & & 0.865 & 0.807 & 0.907 & 8.534 & 0.000 & | & 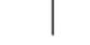 & | & & \\
\hline & & & & & & & & -1.00 & -0.50 & 0.00 & 0.50 & 1.00 \\
\hline \multirow[t]{11}{*}{$\mathrm{B}$} & Studyname & $\underline{\text { Subgroup within study }}$ & \multicolumn{5}{|c|}{ Statistics for œach study } & \multicolumn{5}{|c|}{ Event rate and $95 \% \mathrm{Cl}$} \\
\hline & & & $\begin{array}{c}\text { Event } \\
\text { rate }\end{array}$ & $\begin{array}{l}\text { Lower } \\
\text { limit }\end{array}$ & $\begin{array}{l}\text { Upper } \\
\text { limit }\end{array}$ & Z-value $\mathrm{p}$ & p-Value & & & & & \\
\hline & Lamberts et al. 2017 & $2017-2019$ & 0.647 & 0.527 & 0.751 & 2.389 & 0.017 & & & & & \\
\hline & Goenka et al. 2017 & $2017-2019$ & 0.929 & 0.423 & 0.996 & 1.748 & 0.081 & & & & & \\
\hline & Wedi etal. 2017 & $2017-2019$ & 0.867 & 0.793 & 0.917 & 6.970 & 0.000 & & & & & \\
\hline & Schmidt et al. 2018 & $2017-2019$ & 0.848 & 0.684 & 0.935 & 3.548 & 0.000 & & & & & \\
\hline & Asokkumar et al. 2018 & $2017-2019$ & 0.684 & 0.452 & 0.851 & 1.567 & 0.117 & & & & & \\
\hline & Manta et al. 2018 & $2017-2019$ & 0.944 & 0.904 & 0.968 & 9.502 & 0.000 & & & & & \\
\hline & \multirow[t]{3}{*}{ Golder et al. 2019} & $2017-2019$ & 0.750 & 0.656 & 0.825 & 4.757 & 0.000 & & & & & \\
\hline & & & 0.823 & 0.703 & 0.901 & 4.463 & 0.000 & 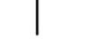 & & ] & & \\
\hline & & & & & & & & -1.00 & -0.50 & 0.00 & 0.50 & 1.00 \\
\hline
\end{tabular}

injection therapy, alone or in combination with each other [20]. However, the total re-bleeding rate after endoscopic treatment was reported to $5-20 \%$ [29-31]. So it is urgent to develop a more effective endoscopic device or technique for UNVGIB. Recently, the OTSC system, as novel management for GI bleeding, has drawn great attention in clinical practice. The OTSC system is a full-thickness suturing device designed for flexible endoscopy. It can be used to close the wound surface of target diseases, such as non-variceal GI bleeding, perforation, fistula, and anastomotic dehiscence [32]. At present, a number of studies reported the usefulness of OTSC system for UNVGIB. In this study, we combined the data from these reports, which allowed us to provide the best evidence on the effectiveness and safety of OTSC system for UNVGIB.

Our study demonstrated that the OTSC system was a technically feasible and effective $(95.7 \%$ technical success rate and $84.2 \%$ clinical success rate) modality in achieving hemostasis of UNVGIB. The OTSC system was relatively safe with a tiny minority adverse events. The high clinical success rate and minimal complication profile indicated that the OTSC system was a viable method for patients with UNVGIB.
There was just one comparative study in our systematic review, which aimed to compare standard endoscopic treatment versus OTSC system [26]. It was demonstrated that OTSC system was associated with greater efficacy and lower re-bleeding rate when compared to standard therapy with through-the-scope clips in patients with recurrent peptic ulcer bleeding after successful initial hemostasis. So the authors favored the use of OTSC system for patients with recurrent bleeding of peptic ulcers. But we still can not reach the conclusion that OTSC system was superior to other endoscopic treatments for recurrent bleeding because of the limited data in our study.

Recently, a systematic review by Ofosu et al. [33] reported a total of 16 studies which involved 475 nonvariceal gastrointestinal bleeding patients treated with OTSC. In their report, the hemostasis rate achieved with primary application of OTSC was 93\% (95\% CI, 8996\%). Similarly, the hemostasis rate achieved with rescue OTSC therapy was 91\% (95\% CI, 84-95\%). Re-bleeding rates after primary OTSC therapy were $21 \%$ (95\% CI, 8$43 \%)$ and $25 \%(95 \% \mathrm{CI}, 17-34 \%)$ with rescue OTSC therapy. Our results were quite close to their report. We 


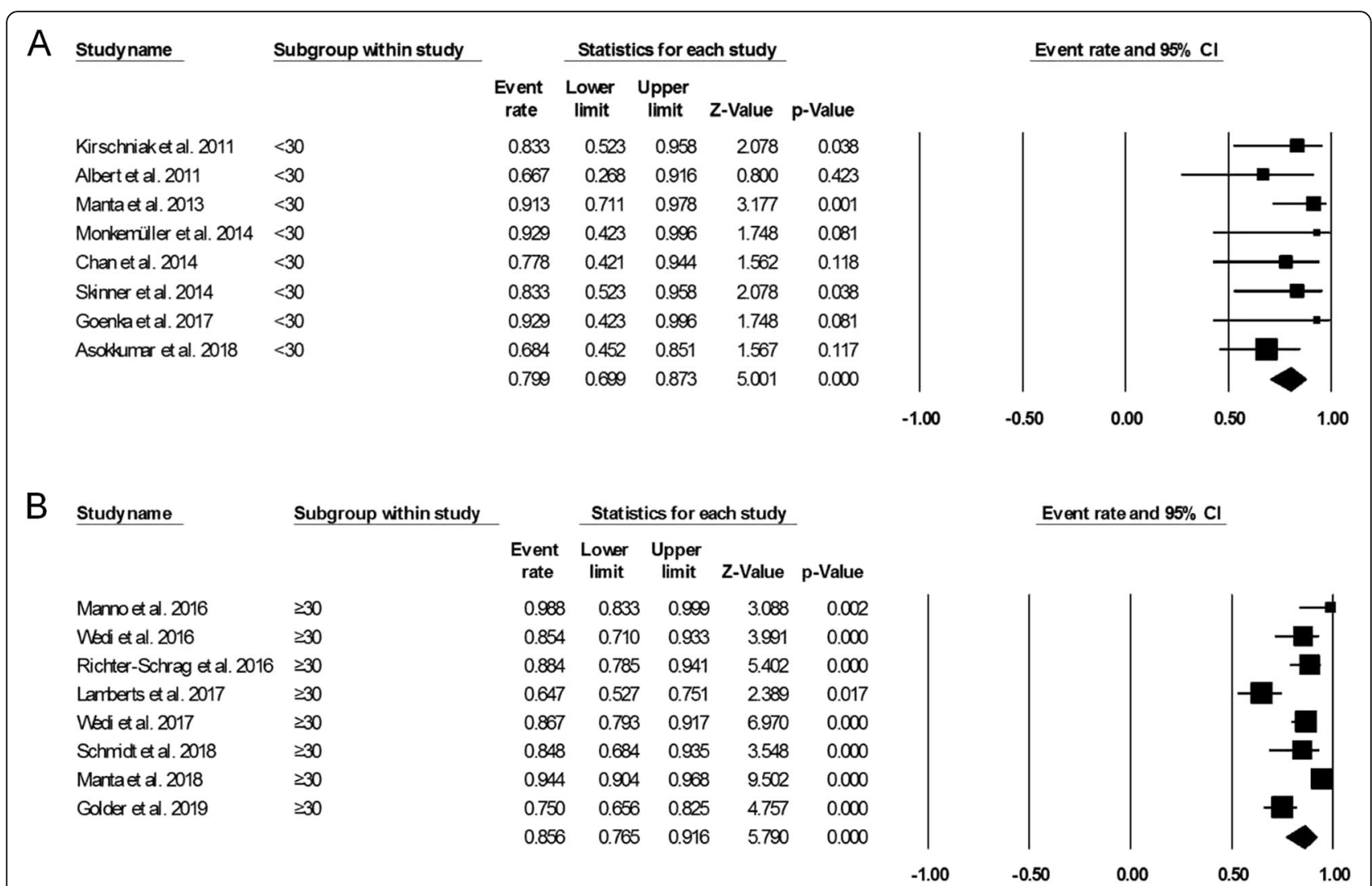

Fig. $\mathbf{6}$ a. Forest plot of clinical success of studies with less than 30 patients. $\mathbf{b}$. Forest plot of clinical success of studies with greater than or equal to 30 patients

Table 3 Quality assessment of included studies

\begin{tabular}{lll}
\hline Study & Downs checklist & Methodological quality \\
\hline Kirschniak et al. [16] & 9 & Low \\
Albert et al. [17] & 9 & Low \\
Manta et al. [18] & 10 & Moderate/low \\
Mönkemüller et al. [19] & 8 & Low \\
Chan et al. [11] & 10 & Moderate/low \\
Skinner et al. [12] & 10 & Moderate/low \\
Manno et al. [20] & 10 & Moderate/low \\
Wedi et al. [21] & 9 & Low \\
Richter-Schrag et al. [22] & 15 & Moderate \\
Lamberts et al. [23] & 11 & Moderate/low \\
Goenka et al. [24] & 9 & Low \\
Wedi et al. [25] & 12 & Moderate/low \\
Schmidt et al. [26] & 20 & High \\
Asokkumar et al. [27] & 14 & Moderate/low \\
Manta et al. [13] & 14 & Moderate/low \\
Gölder et al. [28] & 17 & Moderate \\
\hline
\end{tabular}

found the OTSC system applied as the primary treatment modality in 507 lesions, while 190 lesions as rescue treatment modality after previous endoscopic treatment failure. And most of those patients we included were at high risk of re-bleeding. Five of 15 studies emphasized the OTSC system could reduce significantly re-bleeding rates and mortality in high-risk cohort and could be a first-line treatment for UNVGIB [13, 20, 22, 25, 27]. Conversely, some authors concluded that OTSC system might be considered as a secondary option for high-risk patients after conventional endoscopic hemostasis failed $[11,12,22,23]$. Therefore, OTSC may be considered as first-line treatment for UNVGIB in high risk patients and rescue treatment for initial failed hemostasis with conventional endoscopic methods.

Seven of 16 studies in our systematic review reported the reasons for OTSC treatment failure: 1) delayed closure of OTSC occurring in lesions with large caliber artery and those with deep fibrotic base; 2) shallow placement of OTSC resulting from inadequate suction or premature clip deployment; and 3) misplacement of OTSC because of poor visualization, difficult anatomy, and unstable endoscope position [11, 12, 18, 22, 23, 27, 28]. These failure causes of OTSC above may enlighten its further application in future. 


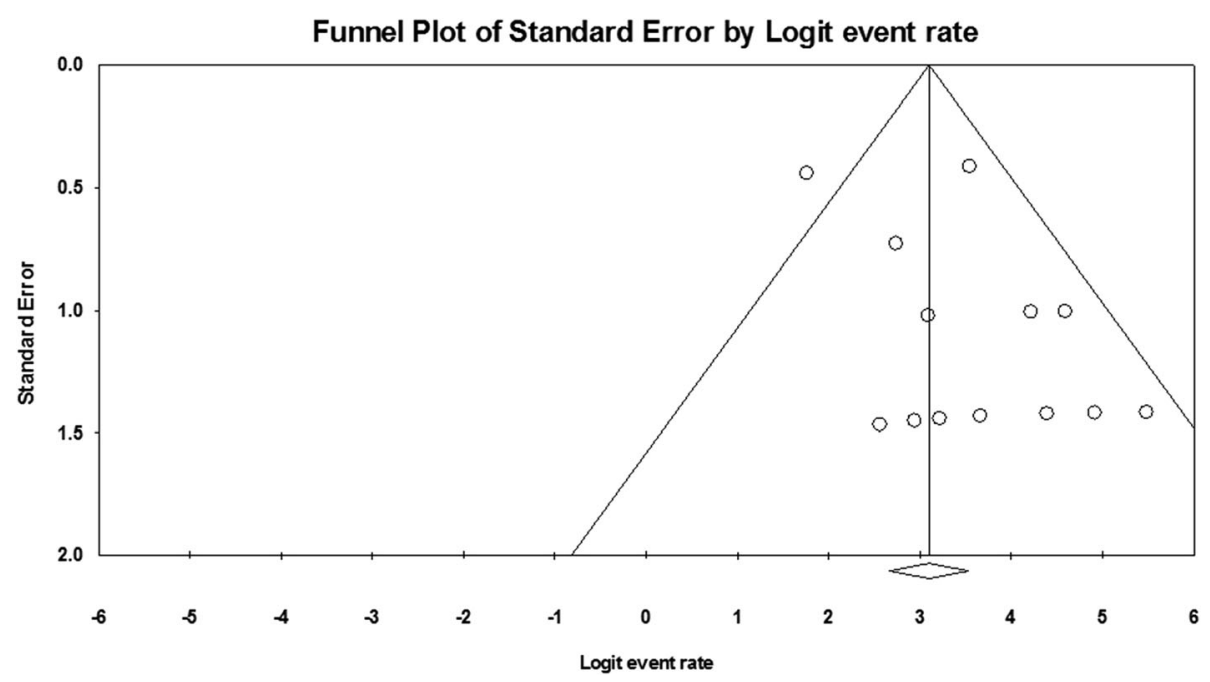

Fig. 7 Funnel plot for publication bias of technical success

The safety of OTSC system for management of UNVGIB should be carefully assessed. Our study revealed that adverse events were rare. Just 2 of 16 studies reported 2 patients experienced the complications. Albert et al. reported one patient with duodenal oozing ulcer experienced a tiny GI leak which was suspected to be caused by the OTSC system, then the patients were converted to the surgical department [17]. RichterSchrag et al. reported lumen obstruction after a duodenal OTSC application. Then, the obstruction released with 3 balloon-dilatations [22]. In addition, there were other OTSC-related complications reported in some studies when OTSC was applied for closure GI perforation or fistula, such as esophageal perforation, acute cholangitis, inadvertent tongue piercing and jejunal stenosis [34-37]. Our study showed $10.9 \%$ of patients died during the follow-up time. Although this data was surprising, only $3.9 \%$ patient died related to OTSC system application failure and most of these patients died due to fatal comorbidity. Gölde et al. deemed that in case of severe recurrent bleeding, the bleeding source could be controlled by endoscopic treatment, but the patient refused any further therapy and died, which was one of the reasons for the high mortality [28].

While our study suggested a promising role of OTSC system for UNVGIB, further consideration is warranted regarding cost. In addition, clinical expertise and unfamiliarity among endoscopists in the small center may factor

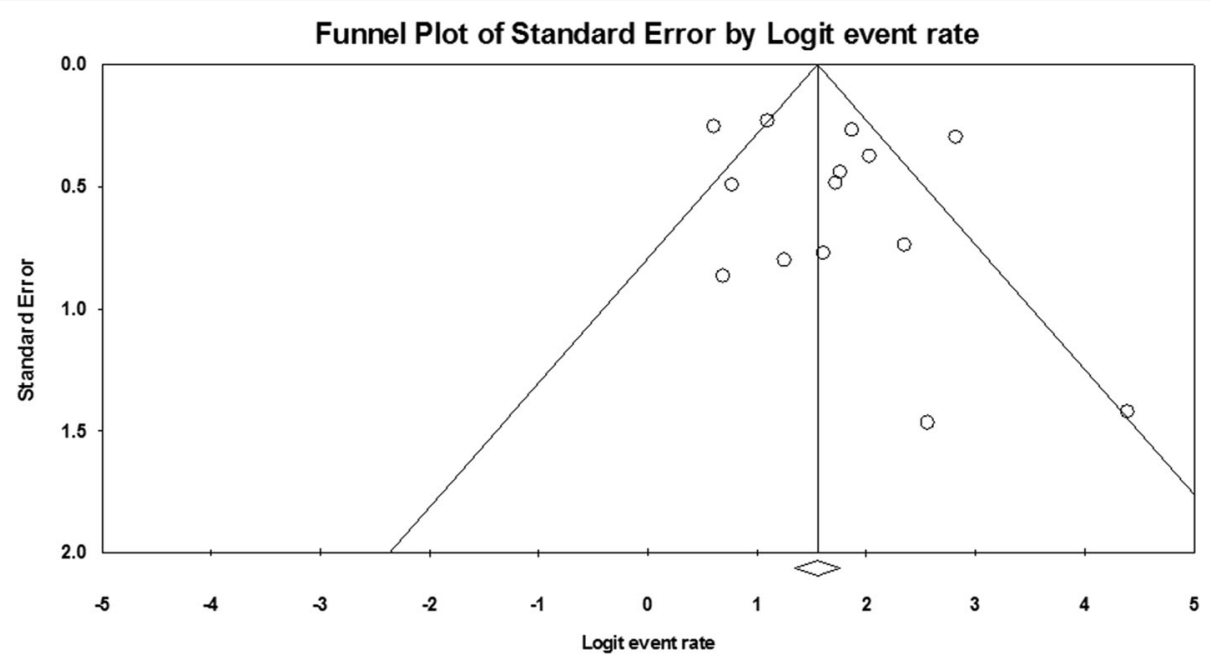

Fig. 8 Funnel plot for publication bias of clinical success 
into variable technical and clinical success results. The expense of this modality for UNVGIB as well as availability remains unclear in our included studies. Future studies are needed to truly assess the cost-effectiveness of OTSC system placement for the management of UNVGIB.

Certainly, we recognized that some limitations in our study. First, our systematic review and meta-analysis were based completely and only on the published literature. We could not get the data of the individual patient, which would allow us to perform more detailed analysis, such as subgroup analysis of OTSC for different etiologies of bleeding. Second, some included studies were missing data for our review variables of interest, such as bleeding classification, lengths of hospital stay and additional therapy modality. Finally, just one literature was high methodological quality study, and our review was lack of comparing OTSC system to other therapy modality.

\section{Conclusions}

Our study demonstrated that the OTSC system was a technically feasible modality and highly efficacious in achieving hemostasis in acute UNVGIB. It is a promising endoscopic technique with high success rate and the rare adverse event. In the future, more randomized controlled trials are needed to compare OTSC to other therapy modality.

\section{Supplementary information}

Supplementary information accompanies this paper at https://doi.org/10. 1186/s12876-019-1144-4.

Additional file 1: Table S1. Detailed search terms of each of search engines used in analysis.

\section{Abbreviations}

Cl: Confidence interval; GI: Gastrointestinal; OTSC: Over-the-scope-clip; SD: Standard deviation; UNVGIB: Upper non-variceal gastrointestinal bleeding

\section{Acknowledgments}

None.

\section{Authors' contributions}

Study conception and design: TXW. Drafting of manuscript: ZCY and TSL. Acquisition of data and critical revision: ZCY and RYT. Revision of manuscript, and final approval of manuscript: LMH, PY, FXS and TXW. All authors have read and approved the manuscript in its current state.

\section{Funding}

This study is independent research funded by the following grants: Medical science and technology plan projects of Zhejiang Province (No. 2017196257), Youth Foundation of Southwest Medical University (No. 0903-00031099), Doctoral research start-up funding project of Affiliated Hospital of Southwest Medical University (No. 16229). The funding bodies have no role in the design of the study and collection, analysis, and interpretation of data and in writing the manuscript.

Availability of data and materials Not applicable.
Ethics approval and consent to participate

Not applicable.

\section{Consent for publication}

Not applicable.

\section{Competing interests}

The authors declare that they have no competing interests.

\section{Author details}

${ }^{1}$ Department of Gastroenterology, Affiliated Hospital of Southwest Medical University, Street Taiping No.25, Region Jiangyang, Luzhou 646099, Sichuan Province, China. ${ }^{2}$ Departmemt of Gastroenterology, Beijing Tsinghua Changgung Hospital, School of Clinical Medicine, Tsinghua University, Beijing, China. ${ }^{3}$ Department of Gastroenterology, Affiliated Hospital of North Sichuan Medical College, Road Wenhua 63\#, Region Shunqing, Nanchong 637000, Sichuan, China.

Received: 17 July 2019 Accepted: 15 December 2019

Published online: 23 December 2019

\section{References}

1. Bardou M, Benhaberou-Brun D, Le Ray I, Barkun AN. Diagnosis and management of nonvariceal upper gastrointestinal bleeding. Nat Rev Gastroenterol Hepatol. 2012;9(2):97-104.

2. Jairath $V$, Barkun AN. Improving outcomes from acute upper gastrointestinal bleeding. Gut. 2012;61(9):1246-9.

3. Lin HJ, Lo WC, Cheng YC, Perng CL. Endoscopic hemoclip versus triclip placement in patients with high-risk peptic ulcer bleeding. Am J Gastroenterol. 2017;102:539-43.

4. Lo CC, Hsu PI, Lo GH, Lin CK, Chan HH, Tsai WL, et al. Comparison of hemostatic efficacy for epinephrine injection alone and injection combined with hemoclip therapy in treating high-risk bleeding ulcers. Gastrointest Endosc. 2006;63:767-73.

5. $\quad$ Sung JJ, Tsoi KK, Lai LH, Wu JC, Lau JY. Endoscopic clipping versus injection and thermo-coagulation in the treatment of non-variceal upper gastrointestinal bleeding: a meta-analysis. Gut. 2007:56(10):1364-73.

6. Taghavi S, Soleimani SM, Hosseini-Asl SM, Eshraghian A, Eghbali H, Dehghani SM, et al. Adrenaline injection plus argon plasma coagulation versus adrenaline injection plus hemoclips for treating high-risk bleeding peptic ulcers: a prospective, randomized trial. Can J Gastroenterol. 2009; 23(10):699-704

7. Yuan $Y$, Wang $\mathrm{C}$, Hunt $\mathrm{RH}$. Endoscopic clipping for acute nonvariceal upperGl bleeding: a meta-analysis and critical appraisal of randomized controlled trials. Gastrointest Endosc. 2008;68(2):339-51.

8. Brandler J, Baruah A, Zeb M, Mehfooz A, Pophali P, Wong KS, et al. Efficacy of Over-the-Scope Clips in Management of High-Risk Gastrointestinal Bleeding. Clin Gastroenterol Hepatol. 2018;16(5):690-6.

9. Kirschniak A, Kratt T, Stuker D, Alexander B, Schurr MO, Königsrainer A. A new endoscopic over-the-scope clip system for treatment of lesions and bleeding in the Gl tract: first clinical experiences. Gastrointest Endosc. 2007; 66:162-7.

10. Moher D, Alessandro L, Tetzlaff J, Altman DG. PRISMA group. Preferred reporting items for systematic reviews and meta-analyses: the PRISMA statement. Int J Surg. 2018:8(5):336-41.

11. Chan SM, Chiu PW, Teoh AY, Lau JY. Use of the over-the-scope clip for treatment of refractory upper gastrointestinal bleeding: a case series. Endoscopy. 2014;46(5):428-31.

12. Skinner M, Gutierrez JP, Neumann H, Wilcox CM, Burski C, Mönkemülle K. Over-the-scope clip placement is effective rescue therapy for severe acute upper gastrointestinal bleeding. Endosc Int Open. 2014;2(1):E37-40.

13. Manta R, Mangiafico S, Zullo A, Bertani H, Caruso A, Grande G, et al. Firstline endoscopic treatment with over-the-scope clips in patients with either upper or lower gastrointestinal bleeding: a multicenter study. Endosc Int Open. 2018;6(11):E1317-21.

14. Downs SH, Black N. The feasibility of creating a checklist for theassessment of the methodological quality both of randomised and non-randomised studies of health care interventions. J Epidemiol Community Health. 1998; 52:377-84.

15. Egger M, Davey Smith G, Schneider M, Minder C. Bias in meta-analysis detected by a simple, graphical test. BMJ. 1997;315:629-34. 
16. Kirschniak A, Subotova N, Zieker D, Königsrainer A, Kratt T. The over-thescope clip (OTSC) for the treatment of gastrointestinal bleeding, perforations, and fistulas. Surg Endosc. 2011;25(9):2901-5.

17. Albert JG, Friedrich-Rust M, Woeste G, Strey C, Bechstein WO, Zeuzem S, et al. Benefit of a clipping device in use in intestinal bleeding and intestinal leakage. Gastrointest Endosc. 2011;74(2):389-97.

18. Manta R, Galloro G, Mangiavillano B, Frazzoni M, Luigi P, Arezzo A, et al. Over-the-scope clip (OTSC) represents an effective endoscopic treatment for acute Gl bleeding after failure of conventional techniques. Surg Endosc. 2013;27(9):3162-4.

19. Mönkemüller K, Peter S, Toshniwal J, Pop D, Zabielski M, Stahl RD, et al. Multipurpose use of the 'bear claw' (over-the-scope-clip system) to treat endoluminal gastrointestinal disorders. Dig Endosc. 2014;26(3):350-7.

20. Manno M, Mangiafico S, Caruso A, Conigliaro R, Bertani H, Mirante VG, et al. First-line endoscopic treatment with OTSC in patients with high-risk nonvariceal upper gastrointestinal bleeding: preliminary experience in 40 cases. Surg Endosc. 2016;30(5):2026-9.

21. Wedi E, Gonzalez S, Menke D. Kruse Elena, Matthes K, Hochberger J. one hundred and one over-the-scope-clip applications for severe gastrointestinal bleeding, leaks and fistulas. World J Gastroenterol. 2016; 22(5):1844-53.

22. Richter-Schrag HJ, Glatz T, Walker C, Fischer A, Thimme R. First-line endoscopic treatment with over-the-scope clips significantly improves the primary failure and rebleeding rates in high-risk gastrointestinal bleeding: a single-center experience with 100 cases. World J Gastroenterol. 2016;22(41): 9162-71.

23. Lamberts R, Koch A, Binner C, Zachäus M, Knigge I, Bernhardt M, et al. Use of over-the-scope clips (OTSC) for hemostasis in gastrointestinal bleeding in patients under antithrombotic therapy. Endosc Int Open. 2017;5(5):E324-30.

24. Goenka MK, Rai VK, Goenka U, Tiwary IK. Endoscopic Management of Gastrointestinal Leaks and Bleeding with the over-the-scope clip: a prospective study. Clin Endosc. 2017;50(1):58-63.

25. Wedi E, Fischer A, Hochberger J, Jung C, Orkut S, Richter-Schrag HJ. Multicenter evaluation of first-line endoscopic treatment with the OTSC in acute non-variceal upper gastrointestinal bleeding and comparison with the Rockall cohort: the FLETRock study. Surg Endosc. 2018;32(1):307-14.

26. Schmidt A, Stefan G, Goetz M, Meining A, Jame L, von Delius S, et al. Overthe-scope clips are more effective than standard endoscopic therapy for patients with recurrent bleeding of peptic ulcers. Gastroenterology. 2018; 155(3):674-86

27. Asokkumar R, Soetikno R, Sanchez-Yague A, Kim Wei L, Salazar E, Ngu JH, et al. Use of over-the-scope-clip (OTSC) improves outcomes of high-risk adverse outcome (HR-AO) non-variceal upper gastrointestinal bleeding (NVUGIB). Endosc Int Open. 2018;6(7):E789-96.

28. Gölder S, Neuhas L, Freuer D, Probst A, Ebigbo A, Braun G, et al. Over-thescope clip in peptic ulcer bleeding: clinical success in primary and secondary treatment and factors associated with treatment failure. Endosc Int Open. 2019;7(6):E846-54.

29. Chung IK, Ham JS, Kim HS, Park SH, Lee MH, Kim SJ. Comparison of the hemostatic efficacy of the endoscopic hemoclip method with hypertonic saline epinephrine injection and a combination of the two for the management of bleeding peptic ulcers. Gastrointest Endosc. 1999;49(1):13-8.

30. Marmo R, Rotondano G, Piscopo R, Bianco MA, D'Angella R, Cipolletta L. Dual therapy versus monotherapy in the endoscopic treatment of high-risk bleeding ulcers: a meta-analysis of controlled trials. Am J Gastroenterol. 2007;102(2):279-89.

31. Hwang JH, Fisher DA, Ben-Menachem T, Chandrasekhara V, Chathadi K, Decker GA, et al. The role of endoscopy in management of acute nonvariceal upper Gl bleeding. Gastrointest Endosc. 2012;75(6):1132-8.

32. Kobara H, Mori H, Nishiyama N, Fujihara S, Okano K, Suzuki Y, et al. Overthe-scope clip system: a review of 1517 cases over 9 years. J Gastroenterol Hepatol. 2019;34(1):22-30.

33. Ofosu A, Ramai D, John F, Barakat M, Sunkara T, Sharma S, et al. Over-thescope-clips as primary and rescue therapy for non-variceal gastrointestinal bleeding: a systematic review and meta-analysis. Minerva Gastroenterol Dietol. 2019;65(1):70-6.

34. Baron TH, Song LM, Ross A, Tokar JL, Irani S, Kozarek RA. Use of an over-thescope clipping device: multicenter retrospective results of the first U.S experience (with videos). Gastrointest Endosc. 2012;76(1):202-8.

35. Mangiavillano B, Morandi E, Masci E. Accidental endoscopic piercing of the tongue with an Ovesco clip. Endoscopy. 2012;44:E221.
36. Voermans RP, Le Moine O, von Renteln D, Ponchon T, Giovannini M, Bruno $\mathrm{M}$, et al. Efficacy of endoscopic closure of acute perforations of the gastrointestinal tract. Clin Gastroenterol Hepatol. 2012;10(6):603-8.

37. Alastal Y, Hammad TA, Nawras M, Khalil BW, Alaradi O, Nawras A. Acute cholangitis following biliary obstruction after duodenal OTSC placement in a case of large chronic Duodenocutaneous fistula. Case Rep Gastrointest Med. 2015;2015:647806.

\section{Publisher's Note}

Springer Nature remains neutral with regard to jurisdictional claims in published maps and institutional affiliations.
Ready to submit your research? Choose BMC and benefit from:

- fast, convenient online submission

- thorough peer review by experienced researchers in your field

- rapid publication on acceptance

- support for research data, including large and complex data types

- gold Open Access which fosters wider collaboration and increased citations

- maximum visibility for your research: over $100 \mathrm{M}$ website views per year

At BMC, research is always in progress.

Learn more biomedcentral.com/submissions 